\title{
Investigation of breastfeeding training based on BASNEF model on the intensity of postpartum blues
}

\author{
Marzieh Akbarzadeh", Sima Kiani Rad ${ }^{2}$, Marzieh Moattari ${ }^{3}$ and Najaf Zare ${ }^{4}$
}

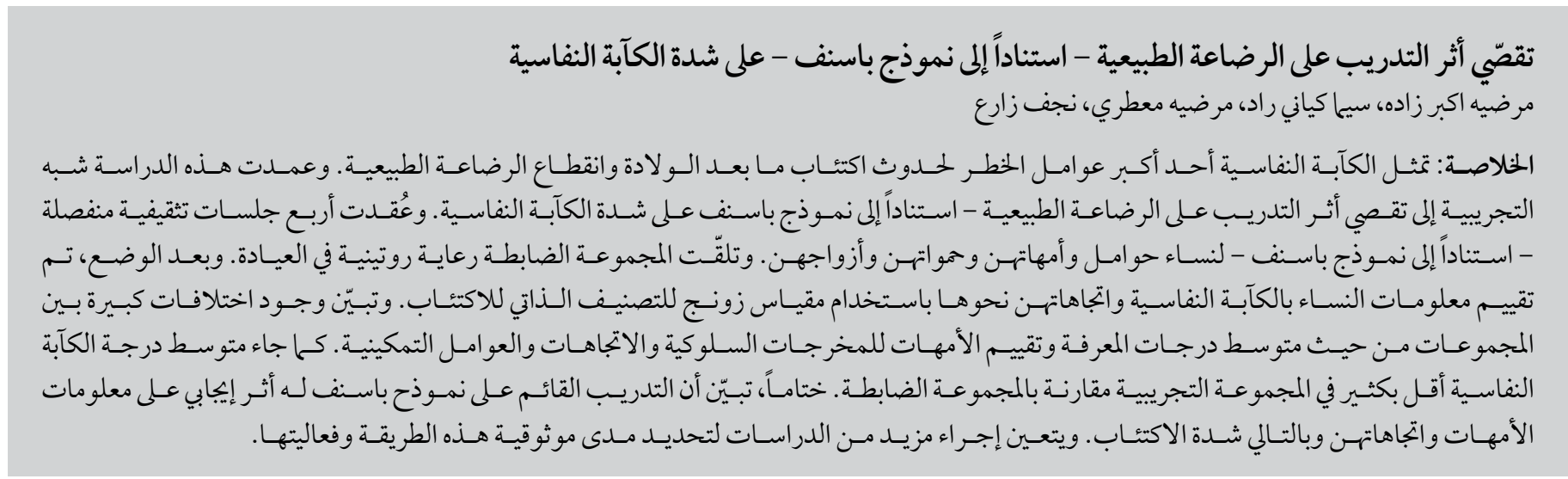

ABSTRACT Postpartum blues is a major risk factor for the incidence of postpartum depression and disruption of breastfeeding. This semi-experimental study investigated the effect of breastfeeding training based on the BASNEF model on severity of postpartum blues in 2012. Four educational sessions based on the BASNEF model were held separately for pregnant women and their mothers, mothers-in-law and spouses. The control group received routine care at the clinic. After delivery, women's knowledge of and attitude towards postpartum blues were evaluated using the Zung SelfRating Depression Scale. There were significant differences between the groups regarding mean scores of knowledge, mothers' evaluation of behaviour outcomes, attitude, and enabling factors. Also, the mean score for postpartum blues was significantly lower in the intervention group compared to the control group. In conclusion, training based on the BASNEF model had a positive effect on maternal knowledge and attitude and, consequently, the intensity of postpartum blues. Further studies are required to determine the reliability and effectiveness of this method.

\section{Étude de l'impact d'une formation sur l'allaitement reposant sur le modèle BASNEF en matière d'intensité du baby} blues

RÉSUMÉ Le baby blues constitue un facteur de risque majeur pour l'incidence de la dépression postpartum et de l'arrêt de l'allaitement au sein. La présente étude semi-expérimentale menée en 2012 avait pour objectif d'examiner l'influence d'une formation sur l'allaitement reposant sur le modèle BASNEF (modèle d'évaluation des croyances, des attitudes, des normes subjectives et des facteurs favorables) en matière de gravité du baby blues. Quatre sessions éducatives reposant sur le modèle BASNEF ont été organisées séparément pour les femmes enceintes et leurs mères, leurs belles-mères et leurs époux. Le groupe témoin a bénéficié de soins de routine à la clinique. Après l'accouchement, les connaissances et l'attitude des femmes en matière de baby blues ont été évaluées sur la base de l'échelle d'autoévaluation de la dépression de Zung. Des différences significatives ont été observées entre les groupes concernant les scores moyens portant sur les connaissances, l'évaluation des conséquences comportementales par les mères, leur attitude et les facteurs favorables. De même, le score moyen pour le baby blues était significativement moins élevé dans le groupe d'intervention que dans le groupe témoin. En conclusion, on peut dire que la formation reposant sur le modèle BASNEF a eu une influence positive sur les connaissances, les attitudes, et par conséquent l'intensité du baby blues des mères. D'autres études sont nécessaires afin de déterminer la fiabilité et l'efficacité de cette méthode.

'Maternal-fetal Medicine Research Centre, Department of Midwifery, School of Nursing and Midwifery, Shiraz University of Medical Sciences, Shiraz, Islamic Republic of Iran (Correspondence to: A. Marzieh: akbarzadm@sums.ac.ir); ${ }^{2}$ Research Centre for Health Sciences, School of Nursing and Midwifery, Shiraz University of Medical Sciences, Shiraz, Islamic Republic of Iran; ${ }^{3}$ Community Based Psychiatric Care Research Center, School of Nursing \& Midwifery, Shiraz University of Medical Sciences, Shiraz, Islamic Republic of Iran; ${ }^{4}$ Department of Biostatistics, Infertility Research Centre, School of Medicine, Shiraz University of Medical Sciences, Shiraz, Islamic Republic of Iran

Received: 02/07/15; accepted: 23/01/17 


\section{Introduction}

Exclusive breastfeeding in the first 6 months of life has been recommended by many organizations, such as World Health Organization (WHO) and American College of Obstetricians and Gynecologists (1).

Many factors affect the decision to start and continue breastfeeding. Continuation of breastfeeding can be encouraged by cultural, social and political factors, mass media, accessibility of health services, social and health staff support (2), traditions, local beliefs and familial factors (3).

Different educational programmes have been considered to increase maternal interest and ability in breastfeeding. To achieve successful behavioural change, the healthcare team should be aware of the effective factors in behaviour formation. The BASNEF model is one of the comprehensive models used for identification of individuals changing behaviour (4). This model focuses on the effect of knowledge, attitude and personal skills on behaviour change and is appropriate for use in developing countries. The BASNEF model comprises beliefs, attitude, subjective norms and enabling factors (5). Generally, individuals change their behaviour if they believe that it has health and economic benefits. A combination of attitudes towards the behaviour and subjective norms results in deciding upon behaviour change (behavioural intention). In this way, the messages affecting the individual's knowledge and how they influence behavioural change are determined. Overall, this approach aims at identification of the factors that enable behavioural change (6).

Postpartum blues is a transient phenomenon involving mood changes that may occur within the first few days after delivery. This phenomenon is accompanied by unstable mood fluctuating between happiness and sadness, excessive sensitivity, crying without reason, restlessness, weakness in concentration, anxiety, irritability and anger (7). On average, $50 \%(15.3-85 \%)$ of mothers experience postpartum blues in the 1st week after delivery (8). However, lack of diagnostic criteria and different research methods have led to different prevalence rates of postpartum blues (9). The postpartum period has the greatest probability for incidence of mood disorders, such as sadness, depression and psychosis, which have negative effects on women's physical and mental health, and consequently, their quality of life $(10,11)$.

There is evidence of a significant decrease in postpartum depression up to 3 months after birth among women who exclusively breastfeed their infants for $\geq 3$ months (12). In contrast, mothers who do not begin or continue breastfeeding are more prone to depression after delivery. Also, mothers who experience depression after delivery are less interested in beginning and continuing with breastfeeding. Postpartum depression may occur following disruption of breastfeeding (13). Nonpharmacological methods are among the most effective ways of coping with stress and depression. Breastfeeding may improve the quality of the maternal-infant relationship, develop safe attachment at the beginning of infancy, and provide a basis for reducing maternal stress. Therefore, the present study aimed to determine the effect of breastfeeding training based on the BASNEF model on postpartum blues in women referred to gynaecology clinics affiliated to Shiraz University of Medical Sciences, Islamic Republic of Iran in 2012.

\section{Methods}

\section{Study population}

This semi-experimental study investigated the effect of breastfeeding training based on the BASNEF model on the severity of postpartum blues in 2012. The study population included pregnant women referred to gynaecology clinics of the selected hospitals affiliated to Shiraz University of Medical Sciences. The inclusion criteria were: primiparity, no complications, gestational age 36-41 weeks, age $18-35$ years, at least secondary school education, no serious physical or mental disorders during the study, living in Shiraz, intending to breastfeed their infants, and willingness to participate in the study. A sample size of 100 was determined based on previous results $(\alpha=0.05, \beta=0.2, P=$ 0.8 ). One hundred pregnant women were selected by purposive sampling and randomly divided into a control $(n=50)$ and an intervention $(n=50)$ group using a table of random numbers.

\section{Interventions}

After selection of the mothers and completion of the demographic questionnaires, 4 educational intervention sessions of 90 minutes based on the BASNEF model were held for the mothers once weekly. These sessions included the advantages of breastfeeding; correct breastfeeding technique; role of breastfeeding in maternal health; effect of breast milk on improvement of children's physical and mental health; signs of sufficiency of milk such as infant weight gain, frequency of urination, sleeping comfortably after breastfeeding; milking and storage techniques; consultation with mothers and their acquaintances regarding breastfeeding; and effect of continuation of exclusive breastfeeding on children's developmental-physical indexes. These sessions were presented through lectures, group discussion, role play, educational pictures, question and answer sessions, pamphlets and DVDs. An educational pamphlet and a CD were also given to the mothers. In addition, 3 educational sessions were held separately for 20 mothers, 14 mothers-in-law and 19 husbands. Both groups completed the BASNEF questionnaire before and immediately, 1 month and 3 months after the intervention. The mothers 
also completed the Zung Self-Rating Depression Scale after the intervention.

Three months after giving birth, mothers were invited by telephone to the nearest clinic for evaluation of BASNEF model parameters. If mothers did not attend on time, they were invited a second time by telephone.

\section{BASNEF questionnaire}

The reliability and validity of the BASNEF questionnaire have been confirmed previously (14), and Cronbach's a coefficients were the basis of the present study. In order to determine the reliability of the questionnaire, a pilot study was conducted on 20 individuals and Cronbach's a coefficients of 0.81 , $0.9,0.78,0.82$ and 0.91 were obtained for beliefs, attitudes, subjective norms and enabling factors, respectively. The BASNEF questionnaire was completed by both groups before and immediately, 1 month and 3 months after the interventions.

\section{Zung Self-Rating Depression Scale}

The Zung Self-Rating Depression Scale was published in 1965 and its reliability and validity have been confirmed in various studies worldwide $(15,16)$. This scale consists of 20 items measuring different aspects of depression, scored from 1 to 4 . In the present study, women were required to mark the sentences that best described their feelings during the previous 2 weeks. The scores increased from left to right for positive feelings, but from right to left for negative ones. Scores $<50,50-59,60-69$, and $>70$ represented normal mood without psychopathology, mild to average depression, average to severe depression, and severe depression, respectively (17). The reliability of this scale was assessed by Khanjani et al. in the Islamic Republic of Iran using a test-retest method with a 15-day interval and a value of 0.92 was obtained (18), which was the basis of the current study. The Zhung Self-Rating Depression Scale was given to mothers in the last training session and the first postpartum visit.

\section{Data analysis}

All data analyses were performed using SPSS version 16 statistical software and analysed using independent $t$ tests. The significance level of $a$ was 0.05 .

\section{Ethical considerations}

This research project was approved by the local Ethics Committee of Shiraz University of Medical Sciences (Proposal No. 91-4605) and written informed consent was obtained from all the participants.

\section{Results}

The mean age of the mothers was 23.86 (standard deviation 4.30) years in the intervention group and 24.4 (4.18) years in the control group. The age range for the 2 groups was 18-34 years. Before the intervention, no significant difference was found between the 2 groups regarding age $(P=0.786)$, education

\begin{tabular}{|c|c|c|c|c|c|c|c|}
\hline \multirow[t]{2}{*}{ Variables } & \multirow[t]{2}{*}{ Groups } & $\begin{array}{c}\text { Before } \\
\text { intervention }\end{array}$ & $\begin{array}{c}\text { After } \\
\text { intervention }\end{array}$ & $\begin{array}{c}\text { After } \\
\text { interventior }\end{array}$ & $\begin{array}{l}1 \text { month } \\
\text { later }\end{array}$ & $\begin{array}{l}1 \text { month } \\
\text { later }\end{array}$ & $\begin{array}{l}3 \text { months } \\
\text { later }\end{array}$ \\
\hline & & \multicolumn{2}{|c|}{ Mean (SD) } & \multicolumn{2}{|c|}{ Mean (SD) } & \multicolumn{2}{|c|}{ Mean (SD) } \\
\hline \multirow[t]{4}{*}{ Knowledge } & Intervention & $58.1(14.4)$ & $97.2(4.3)$ & $97.2(4.3)$ & $94.1(5.1)$ & $94.1(5.1)$ & $91.8(6.5)$ \\
\hline & $P$ & \multicolumn{2}{|c|}{$<0.001$} & \multicolumn{2}{|c|}{$<0.001$} & \multicolumn{2}{|c|}{$<0.001$} \\
\hline & Control & $55.7(14.4)$ & $61.1(14.0)$ & $61.1(14)$ & $58.1(14.3)$ & $58.1(14.3)$ & $57.4(14.7)$ \\
\hline & $P$ & \multicolumn{2}{|c|}{0.063} & \multicolumn{2}{|c|}{0.09} & \multicolumn{2}{|c|}{0.16} \\
\hline \multirow{4}{*}{$\begin{array}{l}\text { Evaluation of } \\
\text { behavioural } \\
\text { outcomes }\end{array}$} & Intervention & $64.8(22)$ & $97.2(8.1)$ & $97.2(8.1)$ & $88.4(21)$ & $88.4(21)$ & $90(21.5)$ \\
\hline & $P$ & \multicolumn{2}{|c|}{$<0.001$} & \multicolumn{2}{|c|}{0.004} & \multicolumn{2}{|c|}{0.399} \\
\hline & Control & $63.6(13.2)$ & $64.4(13.6)$ & $64.4(13.6)$ & $62.8(22.5)$ & $62.8(22.5)$ & $80.4(24.4)$ \\
\hline & $P$ & \multicolumn{2}{|c|}{0.159} & \multicolumn{2}{|c|}{0.598} & \multicolumn{2}{|c|}{$<0.001$} \\
\hline \multirow{4}{*}{$\begin{array}{l}\text { Attitude } \\
\text { towards the } \\
\text { behaviour }\end{array}$} & Intervention & $3.1(0.4)$ & $3.3(0.4)$ & $3.3(0.4)$ & $3.3(0.3)$ & $3.3(0.3)$ & $3.3(0.3)$ \\
\hline & $\mathrm{P}$ & \multicolumn{2}{|c|}{$<0.001$} & \multicolumn{2}{|c|}{0.380} & \multicolumn{2}{|c|}{0.5} \\
\hline & Control & $3.1(0.42)$ & $3.09(0.4)$ & $3.1(0.4)$ & $3.1(0.4)$ & $3.1(0.3)$ & $3.04(0.3)$ \\
\hline & $P$ & \multicolumn{2}{|c|}{0.827} & \multicolumn{2}{|c|}{0.601} & \multicolumn{2}{|c|}{0.04} \\
\hline \multirow{4}{*}{$\begin{array}{l}\text { Enabling } \\
\text { Factors }\end{array}$} & Intervention & $31.2(23.3)$ & $96.3(7.5)$ & $96.3(7.5)$ & $94(8.7)$ & $94(8.7)$ & $95.2(8.0)$ \\
\hline & $P$ & \multicolumn{2}{|c|}{$<0.001$} & \multicolumn{2}{|c|}{0.018} & \multicolumn{2}{|c|}{0.159} \\
\hline & Control & $30.9(21)$ & $35.6(20.6)$ & $35.6(20.6)$ & 39.1 (19.8) & 39.1 (19.8) & $41(20.4)$ \\
\hline & $\mathrm{P}$ & \multicolumn{2}{|c|}{0.019} & \multicolumn{2}{|c|}{0.003} & \multicolumn{2}{|c|}{0.013} \\
\hline
\end{tabular}


level $(P=0.852)$, and occupation $(P=$ 0.952).

There was no significant difference in the control group's mean scores of knowledge immediately, 1 month and 3 months after intervention (Table 1).

For mean scores of evaluation of behaviour outcomes in the intervention group, there was a significant difference before and immediately after intervention, immediately and 1 month after intervention, and 1 and 3 months after intervention (Table 1). In the control group, there was only a significant difference between 1 and 3 months after intervention.

The mean scores of attitude in the intervention group were significantly different before and immediately after intervention (Table 1). However, no significant difference was found immediately and 1 month after intervention, and 1 and 3 months after intervention. In the control group, there was only a significant difference between 1 and 3 months after intervention.

The mean scores of enabling factors in the intervention group were significantly different before and immediately after intervention, and immediately and 1 month after intervention (Table 1). However, there was no significant difference between 1 and 3 months after intervention. In contrast, the control group's mean scores of enabling factors were significantly different before and immediately after intervention, immediately and 1 month after intervention, and 1 and 3 months after intervention.

The mean score of postpartum blues was significantly lower in the intervention group $[31.36$ (7.98)] compared to the control group [37.61 (12.15)] after intervention $(t=3.005, P=0.004)$.

\section{Discussion}

The results of the present study demonstrated a significant difference between the intervention and control groups regarding the mean score of knowledge about breastfeeding immediately after intervention. This implied the effectiveness of educational intervention based on the BASNEF model on increasing maternal knowledge, which is consistent with other studies using the BASNEF model (19). Also, the results immediately, 1 month and 3 months after intervention indicated that the difference remained significant over time. Similarly, Matvienko et al. showed that a 6-month educational intervention improved the participants' knowledge level and prevented them from weight gain (20). The study also showed a significant difference between the intervention and control groups with respect to the change in knowledge. Another study was performed on maternal knowledge and attitude towards breastfeeding in Isfahan, Islamic Republic of Iran in 2008, which showed that the intervention and control groups differed significantly regarding knowledge but not attitude (21). However, our current results were not in agreement with those obtained by Young et al. in a study of health education (22). Those two studies indicated no significant difference between the intervention and control groups with regards to knowledge and attitude. The difference between those and our studies might have been due to the lack of any related models or theories in the design and execution of the educational programme, as well as to the cultural and time differences between the studies.

In our study, the intervention group's attitude towards breastfeeding improved and continued in the followup period. Generally, attitude is not fixed and positive experiences can direct the individuals toward maintenance and improvement of positive attitudes (23). However, Charkazi et al. reported no significant change in attitude (21). It should be noted that training is not sufficient for changing individual attitudes. One appropriate method for changing attitude is expressing one's opinions and watching others' reactions. .

In the current study, the mean score of the intervention group's evaluation of behaviour outcomes immediately, 1 month and 3 months after intervention showed that the differences remained significant over time. This result was similar to that of another study conducted on breastfeeding using the BASNEF model (14).

Our findings revealed a significant difference between the 2 groups regarding the mean score of enabling factors. This might have resulted from accessibility of the enabling factors, such as pamphlets, educational materials and CDs, the researcher's phone number and electric breast pumps (24). In a previous study by Shakespeare et al., mothers mentioned lack of access to health staff as a major problem in continuation of breastfeeding (25). Furthermore, Laveist et al. proposed that the enabling factors were more important than cultural and behavioural differences for changing behaviour (26). Similarly, a study in England demonstrated that husbands' support, acceptance of breastfeeding as a social norm, friends' support, and taking part in educational classes before and after delivery were among the key factors for beginning and continuation of breastfeeding (27). Therefore, it is suggested that individuals who are in close contact with the mothers, such as grandmothers, sisters and husbands, can pass on their experiences and encourage breastfeeding. In the present study, the control group's mean score for enabling factors was also significantly different before and after intervention, which indicates the effectiveness of the healthcare staff in provision of training. Moreland and Coombs also emphasized the role of family physicians and the healthcare team in the success of breastfeeding (28).

We revealed no significant difference between the intervention group's mean scores for subjective norms 
regarding husbands, mothers-in-law and friends before and after intervention, but there was a significant difference in the subjective norms regarding the mothers and healthcare staff. However, no significant difference was found in the control group in this regard. Bertini et al. stated that subjective norms, including the viewpoints of husbands, friends and healthcare personnel were effective in beginning and continuing breastfeeding (27). One other study also demonstrated that the husbands' support and proper attitude towards breastfeeding were effective in breastfeeding premature infants (29). Moreover, a study in England showed that conflict between one's personal expectations and social norms led to social, physical and emotional isolation in the mothers who intended to start breastfeeding their infants (30). Similarly, studies in Tanzania indicated that the individuals around the mother could play an active role in supporting the mother and her decision for breastfeeding (31). Studies in developed countries have demonstrated a positive correlation between paternal support and increase in breastfeeding. Studies in the United States of America on the effectiveness of intervention and mental health education based on the BASNEF model have also revealed an increase in the intervention group's knowledge, attitude and behavioural intention (32).

The present study showed a signifcant difference between the 2 groups with regard to postpartum blues. A previous study indicated that initiation of breastfeeding was accompanied by a decrease in postpartum depression in multiparous women (33). Watkins et al. reported that women who had not breastfed their infants were more likely to experience depression within 2 months after delivery (34).

There is evidence that the hypothalamic-pituitary-adrenal (HPA) axis shows a weak response to stress in breastfeeding women. The function of this axis and cortisol response are associated with progress of depression after delivery. Thus, breastfeeding reduces the response to stress and tension, eventually decreasing the incidence of postpartum depression. Hormones may also play a role in the relationship between breastfeeding and mental function. For instance, oxytocin has shown antidepressive and anxiolytic effects in human and animal models. Prolactin may play a role in the relationship between breastfeeding and depression (33). One study assessed the correlation between postpartum blues and maternal emotional status before delivery, readiness for delivery, and social support after delivery. Among the 131 study participants, $18.3 \%$ experienced depression throughout pregnancy, $61.8 \%$ experienced postpartum blues, and $8.4 \%$ experienced postpartum depression. In that study, postpartum blues was negatively correlated to husbands' and social support, but positively related to emotional status during pregnancy. However, no significant association was found between readiness for delivery and postpartum blues (35).

One of the limitations of the present study was the lack of an appropriate location for holding the training classes, which was to some extent eliminated by group training, reviewing the content in each session, and role playing. One other limitation was utilization of a questionnaire for evaluation of the participants' real attitudes, which was somehow controlled by coding the questionnaires to maintain the participants' privacy. Moreover, not having access to the results of related studies on breastfeeding and the BASNEF model caused us to compare our results to those of studies using this model in other areas. Hence, further studies are required to achieve more comparable results.

In conclusion, we showed the effectiveness of training based on the BASNEF model in increasing maternal knowledge and attitude, encouraging them towards breastfeeding and reducing postpartum blues. Considering the importance of breastfeeding in maternal and infant health and the effectiveness of this model, it is recommended to replace routine training in gynaecology clinics.

\section{Acknowledgements}

The present study was extracted from research project 91-4605. The authors would like to thank Shiraz University of Medical Sciences, the Center for Development of Clinical Research of Nemazee Hospital, Shiraz and Dr. Nasrin Shokrpour for editorial assistance.

Funding: The study was financially supported by the Research Center for Health Sciences, Shiraz University of Medical Sciences.

Competing interests: None declared.

\section{References}

1. McDonald SD, Pullenayegum E, Chapman B, Vera C, Giglia $\mathrm{L}$, Fusch $\mathrm{C}$, et al. Prevalence and predictors of exclusive breastfeeding at hospital discharge. Obstet Gynecol. 2012 Jun;119(6):1171-9. PMID:22617582

2. Spiby H, McCormick F, Wallace L, Renfrew MJ, D'Souza L, Dyson L. A systematic review of education and evidence-based practice interventions with health professionals and breast feeding counsellors on duration of breast feeding. Midwifery. 2009 Feb;25(1):50-61. PMID:17418464
3. Hizel S, Ceyhun G, Tanzer F, Sanli C. Traditional belief as forgotten influencing factors on breast-feeding performance in turkey. Saudi Med J. 2006 Apr; 27(4):12-8. PMID:16598330

4. Kramer MS, Kakuma R. The optimal duration of exclusive breastfeeding: a systematic review. Adv Exp Med Biol. 2004;554:63-77. PMID:15384567

5. Salehi M, Kimiagar SM, Shahbazi M, Mehrabi Y, Kolahi AA. Assessing the impact of nutrition education on growth indices of 
Iranian nomadic children: an application of a modified beliefs, attitudes, subjective-norms and enabling-factors model. $\mathrm{Br}$ Nutr. 2004 May;91(5):779-87. PMID:15137930

6. Habib Ullah J, Ahmed R, Malik JI, Khan MA. Outcome of 7-S, TQM Technique for Healthcare Waste Management. J Coll Physicians Surg Pak. 2011 Dec;21(12):731-4. PMID:22166692

7. Adewuya AO. The maternity blues in western Nigerian woman. Am J Obstet Gynecol. 2005 Oct;193(4):1522-5. PMID:16202750

8. Edhborg M. Postpartum depressive symptoms in family prespective: some indicators experiences and consequences [thesis]. Stockholm: Karolinska Institute: 2004 (https://openarchive.ki.se/xmlui/bitstream/handle/10616/39050/thesis. pdf? sequence $=1$ \&isAllowed $=y$ ).

9. Narasimhaiah G. Manjunath, Giriyappa V, Rajanna. Postpartum blue is common in socially and economically insecure mothers. Indian J Community Med. 2011 Jul;36(3):231-3. PMID:22090680

10. Pesavento F, Marconcini E, Drago D. [Quality of life and depression in normal and in high-risk pregnancy: analysis of a sample of 100 women]. Minerva Ginecol. 2005;57(4):451-60 (in Italian). PMID:16170290

11. Hill PD, Aldag JC, Hekel B, Riner G, Bloomfield P. Maternal postpartum quality of life questionnaire. J Nurs Meas. 2006 Winter;14(3):205-20. PMID:17278340

12. Figueiredo B, Canário C, Field T. Breastfeeding is negatively affected by prenatal depression and reduces postpartum depression. Psychol Med. 2014 Apr;44(5):927-36. PMID:23822932

13. Figueiredo B, Dias CC, Brandão S, Canário C, Nunes-Costa R. . Breastfeeding and postpartum depression: state of the art review. J Pediatr (Rio J). 2013 Jul-Aug;89(4):332-8. PMID:23791236

14. Sharifirad GR, Golshiri P, Shahnazi H, Barati M, Hasanzadeh A, Charkazi AR, et al. The impact of educational program based on BASNEF model on breastfeeding behavior of pregnant mothers in Arak. Arak Med Univ J. 2010;13(1):63-70 (http://amuj.arakmu.ac.ir/browse.php?a_code=A-10-544$1 \&$ slc_lang=en $\&$ sid $=1 \&$ sw=Educational).

15. Hu J, Ai H. Self-esteem mediates the effect of the parentadolescent relationship on depression. J Health Psychol. 2016 Jun;21(6):897-904. PMID:25030796

16. Lee IT, Fu CP, Lee WJ, Liang KW, Lin SY, Wan CJ. Sheu WH. Brain-derived neurotrophic factor, but not body weight, correlated with a reduction in depression scale scores in men with metabolic syndrome: a prospective weight-reduction study. Diabetol Metab Syndr. 2014 Feb 13;6(1):18. PMID:24524285

17. Videbeck SH. Psychiatric mental nursing. Philadelphia: Lippincott; 2001.

18. Khanjani Z, Bashirpoor Khosroshahi K, Bahadori J. The comparative study of personality traits, stress, and depression on individuals suffering from cancer and normal individuals. Urmia Med J. 2013;23(6):619-27 (https://umj.umsu.ac.ir/browse. php?a_id=1569\&sid=1\&slc_lang=en).

19. Hazavehei S1. Sharifirad G, Kargar M. The comparison of educational intervention effect using BASNEF and classic models on improving assertion skill level. J Res Health Sci. 2008 Jun;8(1):1-11. PMID:23343991

20. Matvienko O, Lewis DS, Schafer E. A college nutrition science course as an intervention to prevent weight gain in female college freshman. J Nutr Educ. 2001 Mar-Apr;33(2):95-101. PMID:12031189
21. Charkazi A, Miraeiz SZ, Razzaghnejad A, Shahnazi H, Hasanzadeh A, Badleh MT. Breastfeeding status during the first two years of infants' life and its risk factors based on BASNEF model structures in Isfahan. J Educ Health Promot. 2013 Feb 28;2:9. PMID:24083259

22. Young RD, Haskell Lw, Taylor CB, Fortmann P.S. Effect of community health education on physical activity knowledge, attitudes, and behavior. The Stanford Five-City Project. Am J Epidemiol. 1996 Aug 1;144(3):264-74. PMID:8686695

23. Mack MG, Shaddox LA. Changes in short term attitude toward physical activity and exercise of university personal wellness student. Coll Stud J. 2004 Dec;38(4):587 (http://eric. ed.gov/?id=EJ708800)

24. Down DS, Hausenblas HA. Exercising for two: examining pregnant women's second trimester exercise intention and behavior using the framework of the theory of planned behavior. Womens Health Issues. 2003 Nov-Dec;13(6):222-8. PMID:14675791

25. Shakespeare J, Blake F, Garcia J. Breastfeeding difficulties experienced by women taking part in a qualitative interview study of postnatal depression. Midwifery. 2004 Sep;20(3):251-60. PMID:15337281

26. LaVeist TA, Keith VM, Gutirrez ML. Black/white differences in prenatal care utilization: an assessment of predisposing and enabling factors. Health Service Res. 1995 Apr;30(1):43-58. PMID:7721584

27. Bertini G, Perugi S, Dani C, Pezzati M, Tronchin M, Rubaltelli FF. Maternal education and the incidence and duration of breast feeding: A prospective study. J Pediatr Gastroenterol Nutr. 2003 Oct;37(4):447-52. PMID:14508215

28. Moreland J, Coombs J. Promotion and supporting breast-feeding. Am Fam Physician. 2000 Apr 1;61(7):2093-100 (http:// www.aafp.org/afp/2000/0401/p2093.html).

29. Sweet L, Darbyshire P. Fathers and breast feeding very-lowbirthweight preterm babies. Midwifery. 2009 Oct;25(5):54053. PMID:18191313

30. Mahon-Daly P, Andrews GJ. Liminality and breastfeeding: women negotiating space and two bodies. Health Place. 2002 Jun;8(2):61-76. PMID:11943579

31. Omer-Salim A, Persson LL, Olsson P. Whom can I rely on? Mothers' approaches to support for feeding: An interview study in suburban Dar es Salaam, Tanzania. Midwifery. 2007 Jun;23(2):172-83. PMID:17049695

32. Casper ES. The theory of planned behavior applied to continuing education for mental health professionals. Psychiatr Serv. 2007 Oct;58(10):1324-9. PMID:17914010

33. Mezzacappa ES, Endicott J. Parity mediates the association between infant feeding method and maternal depressive symptoms in the postpartum. Arch Womens Ment Health. 2007;10(6):259-66. PMID:18040595

34. Watkins S, Meltzer-Brody S, Zolnoun D, Stuebe A. Early breastfeeding experiences and postpartum depression. Obstet Gynecol. 2011 Aug;118(2 Pt 1):214-21. PMID:21734617

35. Jung $\mathrm{MH}, \mathrm{Kim}$ JI. A study on the relationship among prenatal emotional status, preparation for delivery, postpartum social support and postpartum blues. Korean J Women Health Nurs. 2005 Mar;11(1):38-45 (https://kjwhn.org/search. php? where $=$ aview\&id $=10.4069 /$ kjwhn $.2005 .11 .1 .38 \&$ code $=01$ 02KJWHN\&vmode=PUBREADER). 